\title{
The accessibility and acceptability of self- management support interventions for men with long term conditions: a systematic review and meta-synthesis of qualitative studies
}

Paul Galdas ${ }^{1 *}$, Zoe Darwin², Lisa Kidd ${ }^{3}$, Christian Blickem $^{4}$, Kerri McPherson ${ }^{3}$, Kate Hunt ${ }^{5}$, Peter Bower ${ }^{4}$, Simon Gilbody ${ }^{1}$ and Gerry Richardson ${ }^{6}$

\begin{abstract}
Background: Self-management support interventions can improve health outcomes, but their impact is limited by the numbers of people able or willing to access them. Men's attendance at existing self-management support services appears suboptimal despite their increased risk of developing many of the most serious long term conditions. The aim of this review was to determine whether current self-management support interventions are acceptable and accessible to men with long term conditions, and explore what may act as facilitators and barriers to access of interventions and support activities.
\end{abstract}

Methods: A systematic search for qualitative research was undertaken on CINAHL, EMBASE, MEDLINE, PsycINFO and Social Science Citation Index, in July 2013. Reference lists of relevant articles were also examined. Studies that used a qualitative design to explore men's experiences of, or perceptions towards, self-management support for one or more long term condition were included. Studies which focused on experiences of living with a long term condition without consideration of self-management support were excluded. Thirty-eight studies met the inclusion criteria. A meta-ethnography approach was employed to synthesise the findings.

Results: Four constructs associated with men's experience of, and perceptions towards, self-management support were identified: 1) need for purpose; 2) trusted environments; 3) value of peers; and 4) becoming an expert. The synthesis showed that men may feel less comfortable participating in self-management support if it is viewed as incongruous with valued aspects of their identity, particularly when activities are perceived to challenge masculine ideals associated with independence, stoicism, and control. Men may find self-management support more attractive when it is perceived as action-oriented, having a clear purpose, and offering personally meaningful information and practical strategies that can be integrated into daily life.

Conclusions: Self-management support is most likely to be successful in engaging men when it is congruent with key aspects of their masculine identity. In order to overcome barriers to access and fully engage with interventions, some men may need self-management support interventions to be delivered in an environment that offers a sense of shared understanding, connectedness, and normality, and involves and/or is facilitated by men with a shared illness experience.

Keywords: Men's health, Long term conditions, Self-management, Masculinity

\footnotetext{
* Correspondence: paul.galdas@york.ac.uk

'Department of Health Sciences, University of York, York YO10 5DD, UK

Full list of author information is available at the end of the article
} 


\section{Background}

The care and treatment of people living with a long term condition (LTC) - a condition or disease that cannot currently be cured but can be managed through medication, therapy and/or lifestyle modification, such as diabetes, arthritis and heart failure - is a major worldwide public health concern. In the UK, over 15 million people currently have a LTC [1] and this number is set to increase over the next decade, with significant rises in multi-morbidity [2].

The increasing burden of LTCs is leading to a shift in emphasis in healthcare delivery towards the promotion of self-management as a critical element of LTC care and a key mechanism for ensuring that future service delivery remains effective, efficient and sustainable [2-4]. Self-management refers to an individual's ability to effectively manage the symptoms, treatment, physical and psychosocial consequences and lifestyle changes associated with living with a LTC [5]. Self-management support (SMS) interventions can be defined as those which focus on developing the abilities of patients to undertake effective self-management through education, training and support to develop knowledge, skills or psychological and social resources [6].

The evidence base on SMS interventions is rapidly expanding and a wide range of interventions have been developed, from skills-based training for specific conditions such as type 1 diabetes (DAFNE [7]) and type 2 diabetes (DESMOND [8]) to assistive technologies such as telehealth and telecare [9]. Other interventions include lay-led support programmes for generic LTCs such as the UK Expert Patient Programme [10] based on the Stanford Chronic Condition programme [11], which aims to promote behavioural change by improving the confidence (self-efficacy) of individuals to manage the physical and psycho-social effects of LTCs. A number of systematic reviews have been carried out on different aspects of SMS. These have focused on interventions targeting specific conditions (e.g. diabetes or mental health) $[12,13]$ types of intervention (e.g. lay-led programmes) [14], or on particular outcomes (e.g. medicines adherence) [15] and have shown benefits in clinical, lifestyle and psychosocial outcomes. Delivered on a large scale, the evidence suggests that SMS interventions have the potential to reduce healthcare costs, achieve effective redistribution of services from hospital to the community, and optimise health outcomes for people with LTCs $[2,16,17]$. However, despite a developing evidence base on the effectiveness of SMS, major knowledge gaps remain, particularly around patient engagement and what works, for whom, and why [4,17].

The effectiveness of SMS is considerably limited by the numbers of patients able or willing to access and engage with available interventions $[4,18,19]$. SMS interventions often fail to engage a significant number, or specific subpopulations, of the wider population because they are not personalized to, or grounded within, the contexts and everyday lives of the individuals and settings in which they interact with health professionals and in which selfmanagement decision making occurs [20].

Men, as a group, are frequently underrepresented at many SMS services [10,14,21-23] and are believed to be poorer self-managers than women [24-29] despite having an increased incidence of many of the most serious and disabling LTCs such as chronic pulmonary disease, diabetes and cardiovascular diseases [25,30]. This is consistent with a growing body of research which shows that risky or unhealthy behaviours (e.g. drinking, smoking, reticence to access health services) are closely related to 'traditional' masculine attitudes that emphasise self-sufficiency, stoicism and robustness [31,32] and are associated with men's poorer health outcomes compared to women [24-29,33]. Recognition of this trend and the increased incidence of serious LTCs in men have led to widespread calls and urgent action for interventions to be specifically targeted at men, in general [25,32,33]. For this reason, we conducted a systematic review and metasynthesis of the qualitative research literature to examine the experiences of, and perceptions towards, SMS among men with LTCs. We aimed to determine whether current SMS interventions are acceptable and accessible to men with LTCs and explore what may act as facilitators and barriers to access of interventions and support activities. Results from a parallel quantitative review of the effectiveness of SMS interventions in men are reported elsewhere.

\section{Methods}

We undertook a systematic search of qualitative literature and employed a meta-ethnography approach to synthesis based on the methods described by Noblit and Hare [34] and Campbell and colleagues [35]. As this was a secondary synthesis of data, ethical approvals were not required.

\section{Search strategy}

A comprehensive electronic search strategy was developed in liaison with information specialists that sought to identify all relevant studies. Five electronic databases were searched in July 2013 (CINAHL, EMBASE, MEDLINE, PsycINFO and Social Science Citation Index).

Due to challenges with methodological indexing of qualitative research [36], the electronic search was complemented by checking reference lists of pertinent papers, and used an adaption of a strategy published elsewhere [37] that included 'thesaurus terms' (keywords indexed in electronic databases, e.g. "Qualitative Research"), 'free text terms' (commonly used research methodology terms searched for in the titles, abstracts, keywords) and 'broadbased terms' (i.e. the broad free-text terms "qualitative", 
"findings", "interview\$" and the thesaurus term "Interviews"). Terms relating to gender were combined with other terms to increase the precision of the strategy (e.g. "men", "male", "masculin\$", "gender", "sex difference\$", "sex factors").

\section{Study screening and inclusion criteria}

Records were initially screened against the broad inclusion criteria by one reviewer (ZD) on the basis of the title and abstract. All articles identified as potentially eligible for inclusion were obtained in full. Attempts were made to identify and obtain published findings for unpublished literature that was otherwise eligible; for example, $\mathrm{PhD}$ theses or conference proceedings. The full text literature was screened independently by two reviewers ( $Z D$ and $P G)$ to identify studies that met all of the following inclusion criteria:

- Presented analysis of qualitative data

- Written in English and published and peer-reviewed in an academic journal

- Participants identified as having one or more LTC

- Data collected in relation to SMS activities and interventions

- Sample either male only or mixed gender (with explicit comparison by gender)

- Sample comprised of adults (or predominately adults)

Studies that used mixed gender samples but did not offer a clear and explicit comparison between men and women were excluded. Also excluded were studies which focused on self-management experiences of people with LTCs more generally (e.g. those which examined 'lived experience' without consideration of SMS).

\section{Quality appraisal and data extraction}

The purpose of quality appraisal in the review was to assess the strengths and weaknesses of the included studies rather than as a basis for inclusion/exclusion. We took the stance of Campbell and colleagues [35] that studies of weaker quality either would not contribute, or would contribute only minimally, to the final synthesis. With that in mind, we used the Critical Appraisal Skills Programme (CASP) tool [38] to assess the quality of various domains (including aims, design, methods, data analysis, interpretation, findings and value of the research). Some additional questions, informed by other meta-ethnography studies [35,39], were used as prompts to facilitate summaries of the main strengths and limitations of each study. Appraisal was conducted by two reviewers independently (ZD and PG) with disagreements resolved through discussion.

\section{Data extraction and synthesis}

All study details (including aim, participant details, methodology, method of data collection, and analysis) were initially extracted by one reviewer (ZD) using data extraction forms previously tested and refined through discussion within the review team following a pilot study of four papers. All data extraction forms were double-checked for accuracy by a second reviewer (PG). We used a metaethnography approach to synthesis that broadly followed the steps described by Noblit and Hare [34]. The analytical process involved three levels of 'construct' [39,40]:

i. First-order constructs: Participant quotes and participant observations, whilst recognising that in secondary analysis these represent the participants' views as selected by the study authors in evidencing their second-order constructs.

ii. Second-order constructs: Study authors' themes/ concepts and interpretations, also described by Noblit and Hare as 'metaphors'.

iii. Third-order constructs: the review team's new interpretations of original authors' interpretations, based on our analysis of first-order and secondorder constructs extracted from the studies.

First-order and second-order constructs from each paper were initially imported into NVivo10 and grouped into broad categories of SMS intervention/activity by one reviewer (ZD) to offer a 'way in' to the synthesis [35]. Each 'group' of studies were then coded inductively by pairs of reviewers, each of whom independently completed matrices to report the second-order constructs and any emerging third-order constructs for each paper. Peer debriefing meetings were then held between reviewers to discuss coding, facilitate the consideration of alternative interpretations, and agree on the second- and third-order constructs, which were subsequently imported into NVivo. Original authors' words were retained in second-order constructs wherever possible. The final third-order constructs were developed during a full-day meeting of the entire review team, where the coded constructs were systematically compared and translated into one another (see Additional file 1). The process involved several iterations until a line of argument' synthesis, which took into account the similarities and differences evident in the studies, was agreed. Finally, the synthesis was refined in discussions with our Patient and Public Involvement (PPI) group which comprised five men with LTCs who had provided guidance and input throughout the review process.

\section{Results}

\section{Study characteristics}

The electronic search strategy identified 6330 unique references. Screening based on title/abstracts identified 
149 articles for full text screening. Dual screening of these full text articles identified 34 studies (reported in 38 articles) that were included in the review. An additional four studies were identified through the checking of reference lists, giving a total of 38 studies (reported in 44 articles) included in the final review (see Figure 1).

Twenty-six of the studies comprised male-only samples; the other 12 studies comprised mixed-sex samples that included explicit comparison between men and women. The majority were conducted in the USA $(n=13$ studies) and the UK $(\mathrm{n}=11)$, with the remainder in Australia $(n=5)$, Canada $(n=5)$, and one in each in Denmark, France, South Africa, and Sweden.

The most common LTC considered in the studies was cancer $(n=22)$, followed by HIV/AIDS $(n=7)$, cardiac conditions $(n=4$ : coronary artery disease $n=1$, heart failure $n=1$, myocardial infarction $n=2$ ), mental health
( $\mathrm{n}=2$ : depression $\mathrm{n}=1$, depression/anxiety $\mathrm{n}=1$ ), arthritis $(\mathrm{n}=1)$, type 2 diabetes $(\mathrm{n}=1)$ and multiple sclerosis $(\mathrm{n}=1)$.

The most common type of SMS interventions were face-to-face support groups (12 studies), followed by 'lifestyle' interventions (11 studies) and internet information and/or online support (5 studies). The remaining studies concerned any experiences of 'any' SMS, including experiences of psychosocial support services, one-to-one support, and peer support, as well as views on potential interventions of perceived benefit (see Tables 1 and 2).

\section{Key themes}

Four interconnected third-order constructs associated with men's experiences of, and perceptions towards, SMS were identified: 1) Need for purpose; 2) Trusted environments; 3) Value of peers; and 4) Becoming an ex-

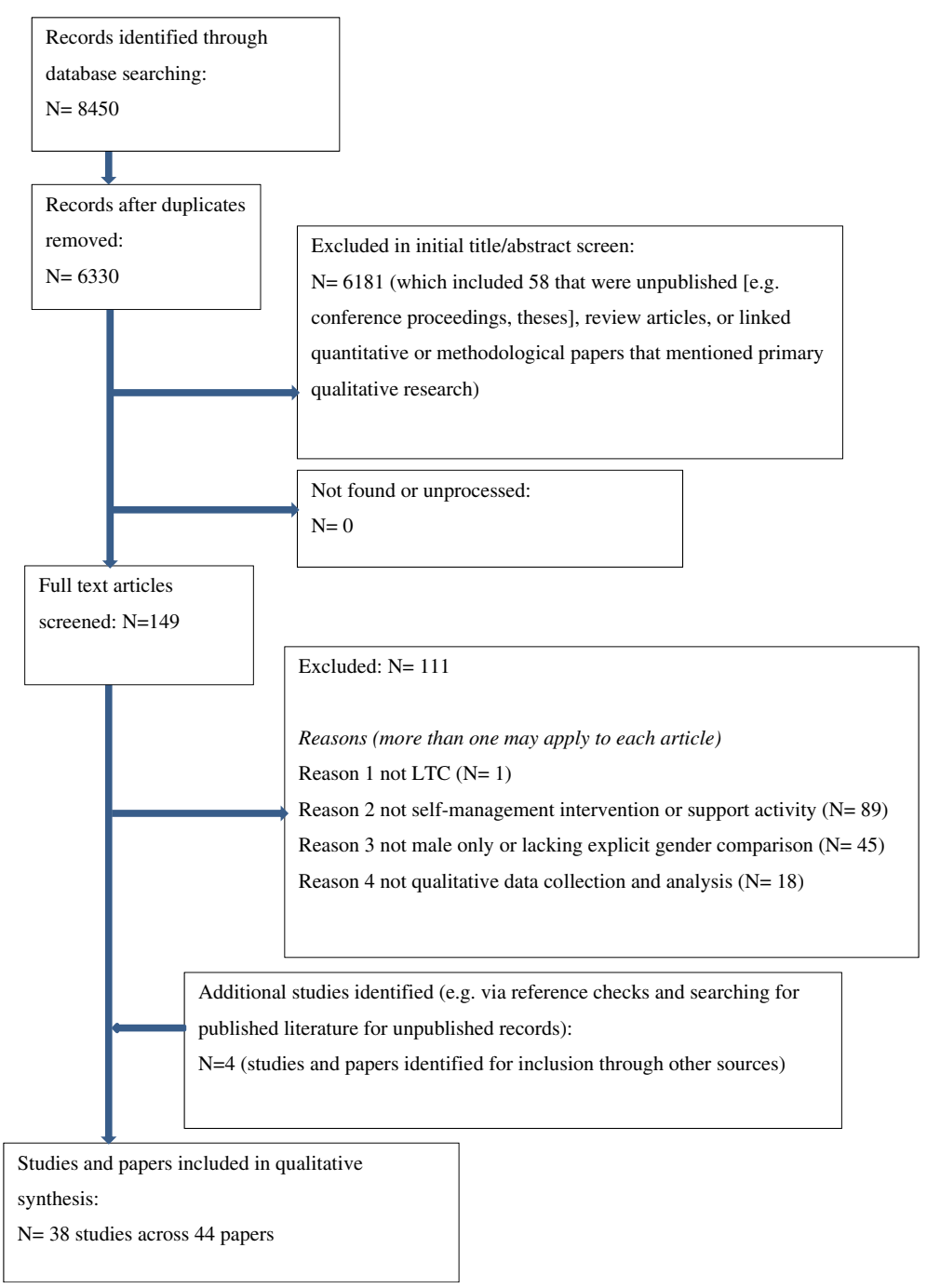

Figure 1 PRISMA flow diagram for systematic literature search. 
Table 1 Categories and descriptions of self-management interventions and support activities

\begin{tabular}{ll}
\hline Self-management category & Description \\
\hline Face-to-face support group & $\begin{array}{l}\text { Any face-to-face support group. This could include peer or professional-led groups and groups that were } \\
\text { time-limited or rolling in nature. These groups usually involved sharing of personal information and experiences, } \\
\text { sometimes including lectures or question-answer sessions. Groups classified here did not include activities such } \\
\text { as physical activity or practising stress management techniques. }\end{array}$ \\
$\begin{array}{l}\text { Internet information and/or } \\
\text { support }\end{array}$ & $\begin{array}{l}\text { Any Internet-based support activity, involving support through forums and discussion boards and/or information, } \\
\text { either through boards or searching websites. }\end{array}$ \\
$\begin{array}{l}\text { Information (including online) } \\
\text { Psychological }\end{array}$ & $\begin{array}{l}\text { Any use of information, regardless of source. } \\
\text { Any intervention or activity with a clear psychological component (e.g. professional counselling) and/or described } \\
\text { by the authors as psychological. }\end{array}$ \\
Lifestyle & $\begin{array}{l}\text { Any intervention or activity that includes components of training and/or education which seek to address } \\
\text { behaviour change (e.g. physical activity, diet, medication-taking). }\end{array}$ \\
\hline Aarious & Any combination of activities (e.g. any self-management services; counselling and peer support).
\end{tabular}

pert. Our line-of-argument synthesis comprising these constructs, summarised below, provides an interpretation of the acceptability of SMS among men with LTCs, and what may act as facilitators and barriers to access of interventions and support services.

\section{Need for purpose}

In order to access and continue to engage with SMS, men may need to feel that a support activity has a clear purpose and addresses an unmet need. SMS that is structured, involves some element of physical activity, offers opportunities to garner new information on self-management, or that is 'action-orientated', can provide a clear purpose that is appealing to men and consistent with a predilection for problem-focused coping $[41,44,45,47,48,55,59,63,72,76,78,82]$. Study authors often contrasted this with a presumed female preference for sharing personal experiences consistent with emotionfocused coping $[44,47,63]$. Structuring meetings around talks by invited speakers, or embracing activities such as activism and lobbying, can also provide a focus for SMS activity that is valued by men [63-65,72,73,75,83].

Men may distance themselves from SMS activities that are considered 'feminine' [61], such as 'touchy-feely' discussions [82]. Being an active rather than passive participant in SMS is preferential for many $[48,52,53,57,66]$ and can offer a way for men to regain some control and reclaim a sense of identity which has been disrupted through chronic illness [52,57].

“...you wouldn't keep coming in if you were going to get nothing out of it. When we were doing the exercises we thought we were getting something out of it. Just having these talks [group discussions] is not doing a lot of good. We still want a bit back" (first-order construct) [48]

"We didn't come just to discuss things". (first-order construct) [41]
Constructive and purposeful discussion, for example, by being problem-focused or sharing and receiving 'factual' information, can be more appealing to men than 'just talking'; offering reassurance, emotional support $[49,55]$ and increasing feelings of control [42].

“...men emphasised the importance of getting practical results from talking therapies in their narratives, as opposed to other forms of therapy which they conceptualised as 'just talking”".

(second-order construct) [57]

Emotional support is, however, a valued component of SMS activity, although men may feel less comfortable than women with reporting this as a motivation for using SMS due to its incongruence with 'traditional' (hegemonic) masculine ideals of stoicism [23,72,73,82,83] and emotional self-sufficiency [53]. Structure and/or group activities can also allow men opportunities to 'open up' emotionally $[41,59,63]$ by approaching emotional issues or mental health "sideways on" [53]. Men can be more comfortable when emotional support arises as a 'by-product' of other shared activities as opposed to it being an explicit component of an SMS intervention. Emotional support that focuses on strength, perseverance, and camaraderie [62], conveyed covertly through humour [41,48] or supportive silence $[41,42]$ can also be attractive to men. Aligned with this is the need to avoid overt challenges to culturallyvalued masculine ideals of independence, strength and control in talking-based activities; supporting the notion that SMS can be made more acceptable to men if it "focuses less on emotional expressiveness and more on instrumental changes and control" [57] and activities are thereby reframed as a way of demonstrating these traditional masculine ideals [52].

"One of the clear barriers to accessing selfmanagement services was the perception among the men that they consisted solely of support groups that 


\begin{tabular}{|c|c|c|c|c|c|c|}
\hline $\begin{array}{l}\text { Study (First } \\
\text { Author, Year, } \\
\text { Country) }\end{array}$ & Aim & $\begin{array}{l}\text { Classification } \\
\text { of support } \\
\text { activity used } \\
\text { in qualitative } \\
\text { synthesis }\end{array}$ & Condition & $\begin{array}{l}\text { Data collection (IV, FG, OP, PO) } \\
\text { and sample size }\end{array}$ & $\begin{array}{l}\text { Methodological } \\
\text { approach }\end{array}$ & $\begin{array}{l}\text { Sample (size, sex, condition details, age, } \\
\text { ethnicity, locality/settlement, SES, } \\
\text { employment, sexuality, relationship) }\end{array}$ \\
\hline $\begin{array}{l}\text { Adamsen }[41] \\
\text { Denmark }\end{array}$ & $\begin{array}{l}\text { Men's experiences of a tailored } \\
\text { intervention involving physical } \\
\text { activity and information relay for } \\
\text { men with cancer }\end{array}$ & lifestyle & cancer - any & $\begin{array}{l}\text { FG } 10 \text { men, PO } 17 \text { men, Total } 17 \\
\text { men }\end{array}$ & $\begin{array}{l}\text { descriptive/ } \\
\text { interpretive }\end{array}$ & $\begin{array}{l}\text { range of cancers and varying stages; mean } \\
\text { age } 56.5 \mathrm{yrs} \text { (range } 21-71 \text { ); ethnicity } \mathrm{n} / \mathrm{r} \text {; } \\
\text { "broad range" of education, employment, } \\
\text { relationship status }\end{array}$ \\
\hline $\begin{array}{l}\text { Arrington [42] } \\
\text { USA }\end{array}$ & $\begin{array}{l}\text { Communication practices of Man } \\
\text { to Man prostate cancer support } \\
\text { groups }\end{array}$ & $\begin{array}{l}\text { support } \\
\text { group (face- } \\
\text { to-face) }\end{array}$ & cancer - prostate & $\mathrm{PO} n / \mathrm{r}$ (20 groups of men) & $\begin{array}{l}\text { discourse } \\
\text { analysis }\end{array}$ & $\begin{array}{l}\text { all "senior citizens"; "almost exclusively } \\
\text { retired, elderly"; no further details reported }\end{array}$ \\
\hline $\begin{array}{l}\text { Baird [43] } \\
\text { USA }\end{array}$ & $\begin{array}{l}\text { Self-care factors influencing } \\
\text { adherence to a cardiac } \\
\text { rehabilitation programme }\end{array}$ & lifestyle & $\begin{array}{l}\text { cardiac - coronary artery } \\
\text { disease }\end{array}$ & IV 5 men & phenomenology & $\begin{array}{l}\text { majority myocardial infarction ( } 4 \text { myocardial } \\
\text { infarction, } 1 \text { sudden cardiac arrest; one was } \\
\text { Post-Cerebral-Vascular Accident (CVA); two } \\
\text { were post-percutaneous-transluminal-coronary } \\
\text { angioplasty, and one was post-coronary-artery- } \\
\text { bypass-graft surgery); aged } 60-70 \text { yrs; } 80 \% \\
\text { Caucasian (4 Caucasian, } 1 \text { African American); } \\
100 \% \text { retired; mix of previous 'blue-collar' and } \\
\text { 'white-collar' occupations; } 100 \% \text { married }\end{array}$ \\
\hline $\begin{array}{l}\text { Barlow [44] } \\
\text { UK }\end{array}$ & $\begin{array}{l}\text { Patients' with multiple sclerosis } \\
\text { experiences of the Chronic Disease } \\
\text { Self-Management Course }\end{array}$ & lifestyle & multiple sclerosis & IV 3 men 7 women & $\begin{array}{l}\text { descriptive/ } \\
\text { interpretive (part } \\
\text { of mixed } \\
\text { methods study) }\end{array}$ & disease duration 4-19 yrs; aged 35-60 yrs \\
\hline $\begin{array}{l}\text { Barlow [45] } \\
\text { UK }\end{array}$ & $\begin{array}{l}\text { Patients' with myocardial infarction } \\
\text { experiences of the Chronic Disease } \\
\text { Self-Management Course and car- } \\
\text { diac rehabilitation }\end{array}$ & lifestyle & $\begin{array}{l}\text { cardiac - myocardial } \\
\text { infarction }\end{array}$ & IV 10 men 9 women & $\begin{array}{l}\text { descriptive/ } \\
\text { interpretive (part } \\
\text { of mixed } \\
\text { methods study) }\end{array}$ & $\begin{array}{l}14 \text { with co-morbidity; median age } 68 \text { yrs } \\
\text { (range 59-74); } 1 \text { employed; majority (16) } \\
\text { married// residing with partner; all had } \\
\text { attended at least } 5 \text { of the } 6 \text { intervention } \\
\text { sessions. }\end{array}$ \\
\hline
\end{tabular}

UK

Daily life experiences of gay men support Bedell [46] with HIV/AIDS living alone in New group (faceYork City

Composition, processes and patients' views of differently

Bell [47] designed and structured cancer

Canada support groups cancer - 1) women with metastatic cancer 2) Colorectal cancer support group (faceto-face) patients; 3) Chinese patients with cancer)
IV 3 men and 17 women. PO
Colorectal group: 14 men, 16 women

Chinese group: 35 men, 61 women descriptive/

interpretive varying severity ( 6 diagnosed with AIDS for $\geq 2$ yrs, 2 not yet developed); all had prior/ current difficulty with daily activities; aged 25-50 yrs; majority white (6 white, 2 African American); all urban; majority "middle-class": education ranged 1 yr college to doctorate:

descriptive/ $\quad 4$ employed, 3 on public assistance, 1 interpretive neither; all gay; all lived alone.

interview sample: time since diagnosis 3 months-3 yrs, 13 in treatment, 7 post treatment; time in group 1 month-4yrs; median age 50 s (range 40s-70s); ethnicity n/r metastatic observation sample: 0 men, 25 women; 25 in treatment; median age 50s (range 30s-60s); majority white; colorectal observation sample: 14 men, 16 women; 1 pretreatment, 8 in treatment, 12 post

treatment; median age 50s (30s-70s); majority 
Men's experiences of a lifestyle

intervention for men with prostate

Bourke [48] cancer undergoing androgen

UK

Broom [49] experience of prostate cancer and

Australia suppression therapy

Impact of Internet use on disease

lifestyle

Internet

(information

and/or

the doctor-patient relationship cancer - prostate

cancer - prostate

V33 men

white; Chinese observation sample: 35 men 61 women 5 pretreatment, 30 in treatment, 15 post treatment; median age 50 s (20s-80s); all Chinese.

all T3-T4 prostate cancer receiving androgen suppression therapy $\geq 6$ months; details $n / r$ but linked trial reports for intervention group of 25: mean treatment 30 months (sd 31); mean age 71.3 yrs (sd

descriptive / interpretive $6.4)$

"range" of prognoses and treatments; interpretive

$\mathrm{n} / \mathrm{r}$ for interview sample therefore based on 19 men taking part in intervention. Time since diagnosis mean 68.9 months (sd 51.2, range 1-167); majority had hormone treatment; range of surgery and radiotherapy (16 received hormone therapy incl. 9 ongoing; 11 external beam radiation therapy, 3 brachytherapy, 3 radical prostatectomy surgery, 1 orchidectomy); mean age $67.0 \mathrm{yrs}$ (sd 6.5 yrs, range 58-83); $79 \%$ completed university, college, or vocational training; $37 \%$ employed, $63 \%$ retired; $84 \%$ married or Men's experiences of a mindfulness-based cognitive therChambers apy group intervention in men [50] Australia with advanced prostate cancer

Chenard [51] Impact of stigma on self-care beUSA haviours of HIV-positive gay men

psychological cancer - prostate support group (faceto-face)

HIV/AIDS

Perceived barriers to using

psychosocial support services in

Corboy [52] men with cancer living in rural

Australia

Australia

various

cancer - prostate

Men's experiences of depression and anxiety groups and the role of

Cramer [53]

UK support

support

group (face-

to-face)

depression/anxiety
IV 12 men

V 15 men, FG 5 men (1 group), Tota 20 men

$\checkmark 9$ men (82 surveyed and subsample interviewed)

V 17 men, PO 30 (4 groups, unclear if this includes some women), Tot 38 (may include women)

IV 20 women (intended as mixed but only managed to recruit women) linked study cancer - any

\section{Dickerson}

2006 [54] USA Experiences of patients with cancer Internet

(linked study using the Internet for information (information

[55])

support) including symptom management descriptive / interpretive separated.

\section{grounded}

theory

all HIV+ $\geq 1 \mathrm{yr}, 85 \% \geq 5 \mathrm{yrs}$; median age 44 yrs (range $26-62 ; 70 \%$ over $30 \mathrm{yrs}$ ); all gay.

men with 'any' cancer eligible but al participants had prostate cancer; mean age 69 yrs (sd 9.3); all rural (5 accessible, 4 moderately based on ARIA+ classification); all married: 2 employed, 1 sick leave, 6

descriptive /

details $n / r$; sampling described as aiming to increase ethnic diversity and diversity in

descriptive / interpretive

type of help sought

various cancer types (11 breast, 3

gynecologic, 1 gastrointestinal, 3

lymphomas, 2 hematological; 7 new diagnosis, 7 in treatment 6 survivors (>5 yrs); mean age 52.3 yrs (sd 8.7, range 34-65); mean education 15 yrs (sd 2, range 12-18); phenomenology mean 14 hours weekly Internet use (sd 12 
majority prostate cancer (14 prostate, 1 leukemia): 1 new diagnosis, 4 in treatment 10 survivors ( $>5$ yrs): mean age 63 yrs ( 10, range 47-78); mean education 17 yrs (sd 3, range 12-20): mean 11 hours weekly

Internet

Dickerson [55] Experiences of men with cancer and/or using the Internet

(information

Phenomena of participation and non-participation in nurse-led clinic for chronic heart failure, as ob-

Eldh [56] served in visits and experienced by

Sweden patients and nurses

cardiac - heart failure

3 men

Experiences of men and women with depression in articulating

Emslie [57] emotional distress and engagin

UK with health professionals

IV 34 men (total sample is 43 but paper focus is on 34 who did use complementary and alternative medicine (CAM) information in

Evans [58] UK men with cancer
Motives for regular physical activity in men and women with type ?

Ferrand [59] diabetes using the French patients

France association Move for Health

Canadian Punjabi Sikh men's experiences of adopting lifestyle

Galdas [60] changes following myocardial

Canada

\begin{abstract}
infarction
\end{abstract}
descriptive/ interpretive

descriptive/ interpretive diabetes - type 2

IV 9 men 14 women
Internet use (sd 10, range 1-35); mean 7 yrs using Internet (range 1-10); 10 attend 'Us,

phenomenology Too' face-to-face support group

classed as II/III using New York Heart Association classes of heart failure; aged 53,

phenomenology 77, 79 yrs

majority (34/38) experienced multiple/ prolonged depressive episodes; 18/38 hospitalised; 10/38 bipolar depression; wide age range $(<30-66+; 3<30,1430-40,1141$ 55,6 56-65, 4 66+ yrs); majority White British (33/38 - others 1 each of Black, Asian, South European, North European, American).

various cancer types (10 colorectal, 10 prostate, 3 lung, 11 other - thymic, tonsillar, pancreatic, bone, lymphoma, bladder, renal, oesophageal, leukaemia); varying stages (10 localised, 10 remission, 8 metastatic 6 palliative care); mean age 57 yrs (range 31-83), all white; 'range' of manual, non-manual and professional occupational backgrounds (over half professional); 22 used CAM before diagnosis

men: 6 diagnosed $\geq 5$ yrs; 6 medicated including 2 insulin; mean age 67.0 yrs (sd 6.1); 6 post-secondary education; 1 employed, 8 retired; 7 married, 1 widowed, 1 never married; women mean 56.3 yrs (sd 9.5), total range 3578 yrs; 13 diagnosed $\geq 5$ yrs; 10 medicated including 4 insulin: mean age 56.3 (sd 9.5): 4 post-secondary education; 3 employed, 7 retired, 4 homemaker; 7 married, 1 widowed 5 separated/divorced, 1 never married.

descriptive/ majority reported comorbidity (10 diabetes, 8 high blood pressure, 7 high cholesterol, 3 depression); mean age 65.7 yrs (range 41-86); all Canadian Punjabi Sikh; lived in infarction 
Factors influencing utilisation of

Gibbs [61] self-management services in men

Australia

with arthritis

various

Work as a barrier to accessing

Gibbs [23] self-management services in men

various

Cof ways in which men - Internet

with prostate cancer and women (information

breast cancer share issues online

Comparison of men's experiences

of prostate cancer self-help groups support

Gray [63] and women's experiences of breast group (face-

Canada

cancer self-help groups

to-face)

cancer - prostate (men)

and breast (women)

I V12 men, IV/FG 27 women

support

\section{Canada}

(linked study Men's experiences of prostate

to Gray [63]) cancer self-help groups

\section{Gray [65]}

(linked study Women's experiences of breast

to Gray [63]) cancer self-help groups

group (face-

to-face)

support

group (face

to-face)

various arthritis

IV 17 men

arthritis

IV 17 men

cancer - prostate (men) and breast (women)

OP 77 men (591 postings) 69 wome (272 postings)

grounded theory (and participatory research)

grounded theory (and participatory research)

descriptive/ interpretive

(part of mixed methods) disability income; 24 married, 3 widowed 15 attended cardiac rehabilitation.

time since diagnosis 4 months-25 yrs; varied health status (self-reported 3 poor 8 fair, 6 good); median age 41-60 yrs (2 18-25, 3 26-40, 7 41-60, 3 61-75, 2 75+); majority Anglo/Celtic (12 Anglo/Celtic incl. 1 also Aboriginal; 1 UK/European, 1 Greek, 1 Chilean, 1 Italian, 1 Filipino/Asian); varied education (1 primary school only, 5 completed secondary, 1 passed secondary, 7 vocational, 3 university, $3 \mathrm{n} / \mathrm{r}$ ); 9 employed, 6 retired, student, 1 unemployed; range of employment roles (health senvices, research, managerial, information technology, motor mechanics, farming); sexuality not asked but 1 homosexual, 1 bisexual, other referred to female partners althoug acknowledge may not identify as heterosexual; varied involvement in different programmes)

see 2005 paper (pooled)

no sample characteristics due to methods; however quality of writing in postings

suggested "reasonably well educated and articulate"

men: "representation from among longterm survivors and men with advanced disease"; aged 45-80; women: range of time since diagnosis $(4<1$ year, $11<3 y r s, 10$ longer term); range of severity including 6 with recurrence; aged $33-73$ yrs ( 15 aged $<50$ ); all white reflecting groups; "predominantly middle class and well educated" (3 had less that high school).

descriptive/ nterpretiv

see above

phenomenology 
Iredale [67] Perceptions of information needs in men with breast cancer
Experiences of counselling and

Harris [66] peer support services in gay men Canada with HIV/AIDS information cancer - breast (male)
IV 30 men (subsample of n161 men surveyed in full study) descriptive only (supplement to quantitative study)

\section{support}

Kendall [68] groups in gay men with HIV/AIDS

Men's experiences of a prostate

Kronenwetter cancer lifestyle trial for men with

\section{[69] USA}

early prostate cancer

Men's experiences of a nurse-led

Martin [70] workshop for men with testicular

UK cancer

Phenomenon of therapeutic

Mfecane [71] citizenship in HIV/AIDS support South Africa groups, as observed in visits and group

(face-to-face) HIV/AIDS IV 29 men

mean 9.75 yrs since diagnosis (range 4-15): mean age 43 yrs (range 27-56); range of education (4 some high school credits, 5 completed high school, 3 "completed some" university/college education); 7 employed, 2 retired, 3 not working; varied income $(5<\$ 20,000,3 \$ 30,000-\$ 49,999,1\rangle$ $\$ 50,000,3 \mathrm{n} / \mathrm{r}$ ); all gay (5 previously married to women); all involved in local communitybased agencies; most reported following their antiretroviral medications; 6 men had used peer support 1-2 times per week for 8 yrs on average; 7 men had received counselling 1-2 times per fortnight for 4 yrs on average.

details for interview sample $n / r$; details for full sample surveyed (n161): mean 35 months since diagnosis (range 2-120); 55\% current breast cancer; mean age $67.3 \mathrm{yrs}$ (range 27-88); $64 \%$ secondary education or above; $78 \%$ married/ residing with partner, $8 \%$ single, $6 \%$ divorced/separated, $8 \%$ widowed.

mean 3 yrs 2 months since HIV diagnosis (range 3 months-9 yrs); range of disease severity (8 asymptomatic; 8 mild, transient symptoms; 8 "full-blown AIDS, not terminal", 8 "full-blown AIDS in terminal stage"); mean age 37 yrs (range 25-58); majority Caucasian (27 Caucasian, 2 African American); majority highly educated (mean 16 yrs education; only 1 without college education); 53\% employed, 46\% disability allowance; all gay; 11 in a relationship (length ranging 1

month-14 yrs); $31 \%$ strong family support, $46 \%$ strong friend support but "in general

descriptive/ interpretive

descriptive/ interpretive

descriptive/ interpretive

IV 25 men: PO n n/r (14 months, presumably includes some women) did not feel well-supported". mean 3

HIV-support groups attended (range 1-8).

mean age 67 yrs (range 50-85); majority

Caucasian (>90\%); majority college education, university education or "specialised training" (>90\%); "over half" retired; 21 (81\%) had "partners/spouses".

mean age 35 yrs (range 29-45)

interview sample: aged $28-50 \mathrm{yrs}$; all South

African; all rural; all "poor, working-class ethnography community"; majority unemployed; 
Table 2 Characteristics of included studies (Continued)

experienced by men in rural South

Africa

Oliffe [72] Factors influencing sustainability of support

sustainability of group (faceprostate cancer support groups $\quad$ to-face) $\quad$ cancer - prostate

cancer - prostate

PO 333 men (15 groups of men and partners)

rostate cancer support groups simultaneously facilitate health promotion and illness

support

Oliffe [72] demotion

group (face-

to-face)

cancer - prostate

PO 333 men (15 groups of men and partners), IV 52 men, Total 333 men

ethnography

How men who attend prostate cancer support groups engage with health literacy and

consumerism

support

Oliffe [73]

cancer - prostate

Acceptability of a brief self-led psy-

Ramachandra chological intervention in patients

[74] UK cancer - metastatic prostate (men) and metastatic breas

psychological (women) $\checkmark$ unclear if 4 men 3 women or 3 men 2 women (46 in total trial - 24 men 22 women; unclear if feedback at 6 weeks or 12 weeks)
PO $n \mathrm{n} / \mathrm{r}$ (16 groups of men and partners), IV 54 men, Total n n/r approximately half single (6 married, 4 cohabitating, 3 partners living apart 12 single); $\geq 1$ child but minority lived with their childen.

details of group members $n / r$

interview sample: mean 6.8 yrs since diagnosis; majority received treatment (49); mean age 70 yrs (range 53-87); 25 AngloCanadian, 25 Northern European; majority retired (42): all attended $\geq 2$ meetings in past year (inclusion criteria); mean $5.3 \mathrm{yrs}$ accessed support groups; 16 were longterm members (had been attending for more than 12 months), and 16 were shortterm members (had been attending for less than 12 months): 20 held leadership roles (e.g. facilitator, secretary).

interview sample: majority received treatment (50); mean age 71 yrs (range 5387); all Canadian, "many" Northern European ancestry; majority retired (44); all attended $\geq 2$ meetings in past year (inclusion criteria): 16 were long-term members (had been attending for more than 12 months), and 16 were short-term members (had been attending for less than 12 months), 22 held ethnography leadership roles (e.g. facilitator, secretary).

descriptive only (supplement to interview sample details $\mathrm{n} / \mathrm{r}$; full trial details: quantitative men: mean age $72.4 \mathrm{yrs}$; women: mean age study) $\quad 60.8 \mathrm{yrs}$.

all advanced diagnoses; 10 symptomatic HIV (including 3 with severe complications), 15 diagnosed with AIDS; age ranged 20-56 yrs (7 20s, 11 30s, 6 40s, 1 50s); majority white (2 African American); 12 "attended college or completed college degrees"; 20 urban; all gay; 16 had used support groups at some time, including 9 briefly ("usually

support

Sandstrom Utilisation of peer support groups group (face

HIV/AIDS IV 25 men

grounded

theory

1-4 months") and 7 for $\geq 1$ year.

interview sample details $\mathrm{n} / \mathrm{r}$; online postings sample details $\mathrm{n} / \mathrm{r}$. Ziebland 2004 (cited by authors) reports interview sample details for 49 men and 37 women as respective mean IV 52 men 47 women, OP 900 men Compare the language of men and Internet women with cancer in research (information Seale [76] UK groups and/or support) cancer - prostate (men) and breast (women) descriptive / age 62 yrs (range 51-83) and 44 yrs (range interpretive
153 women, Total 952 men, 200

women

IV 4 men 7 women 
Table 2 Characteristics of included studies (Continued)

\begin{tabular}{|c|c|c|c|c|c|c|}
\hline $\begin{array}{l}\text { Seymour- } \\
\text { Smith [20] UK }\end{array}$ & $\begin{array}{l}\text { How men and women negotiate } \\
\text { their identities as members of } \\
\text { cancer self-help groups }\end{array}$ & $\begin{array}{l}\text { support } \\
\text { group (face- } \\
\text { to-face) }\end{array}$ & $\begin{array}{l}\text { cancer - testicular (men) } \\
\text { and breast (women) }\end{array}$ & & $\begin{array}{l}\text { discourse } \\
\text { analysis }\end{array}$ & $\begin{array}{l}\text { men aged } 26-31 \text {, women aged } 33-64 \text { yrs; all } \\
\text { White UK; men's sample includes } 1 \text { group } \\
\text { leader. }\end{array}$ \\
\hline $\begin{array}{l}\text { Smith } 2002 \\
\text { [77] USA }\end{array}$ & $\begin{array}{l}\text { Views of African American men } \\
\text { with prostate cancer who do not } \\
\text { use the Man to Man support group }\end{array}$ & $\begin{array}{l}\text { support } \\
\text { group (face- } \\
\text { to-face) }\end{array}$ & cancer - prostate & FG 4 men & $\begin{array}{l}\text { descriptive only } \\
\text { (supplement to } \\
\text { quantitative } \\
\text { study) }\end{array}$ & $\begin{array}{l}\text { all African American; all members of '100 } \\
\text { Black Men' organisation. }\end{array}$ \\
\hline $\begin{array}{l}\text { Sullivan [78] } \\
\text { USA }\end{array}$ & $\begin{array}{l}\text { Comparison of communication } \\
\text { practices of men with prostate } \\
\text { cancer and women with ovarian } \\
\text { cancer supporting each other } \\
\text { online }\end{array}$ & $\begin{array}{l}\text { Internet } \\
\text { (information } \\
\text { and/or } \\
\text { support) }\end{array}$ & $\begin{array}{l}\text { cancer - prostate (men) } \\
\text { and ovarian (women) }\end{array}$ & $\begin{array}{l}\text { OP } 176 \text { men ( } 616 \text { postings) } 134 \\
\text { women ( } 1256 \text { postings) (not } \\
\text { extracted re: HCPs and others) }\end{array}$ & $\begin{array}{l}\text { descriptive/ } \\
\text { interpretive }\end{array}$ & sample details not known (due to methods) \\
\hline $\begin{array}{l}\text { Trapp [79] } \\
\text { USA }\end{array}$ & $\begin{array}{l}\text { Men's preferences for cancer } \\
\text { support groups }\end{array}$ & $\begin{array}{l}\text { support } \\
\text { group (face- } \\
\text { to-face) }\end{array}$ & cancer - any & IV 5 men & $\begin{array}{l}\text { descriptive/ } \\
\text { interpretive }\end{array}$ & $\begin{array}{l}\text { various cancer types ( } 2 \text { melanoma, brain } \\
\text { cancer, lymphoma, leukemia); various stages } \\
\text { ( } 2 \text { metastatic, } 1 \text { stage III); } 4 \text { had previous } \\
\text { cancer diagnosis; aged } 30-69 \text { yrs (30, 62, 62, } \\
64,69) \text {; all Caucasian USA; urban; majority } \\
\text { highly educated ( } 1 \text { high school, } 2 \text { graduate, } \\
2 \text { postgraduate); all had been employed } \\
\text { (some retired/unable to work); } 2 \text { married, } 2 \\
\text { single, } 1 \text { widowed }\end{array}$ \\
\hline $\begin{array}{l}\text { Vanable [80] } \\
\text { USA }\end{array}$ & $\begin{array}{l}\text { Views of men with HIV who have } \\
\text { sex with men about sexual risk } \\
\text { reduction programmes, to develop } \\
\text { a tailored intervention }\end{array}$ & various & HIV/AIDS & IV 21 men, FG 31 men, Total 52 men & $\begin{array}{l}\text { descriptive/ } \\
\text { interpretive }\end{array}$ & $\begin{array}{l}\text { mean } 8 \text { yrs since diagnosis; } 50 \% \text { reported } \\
\text { undetectable viral load; mean age } 41.4 \text { yrs } \\
\text { (sd } 8.1 \text {, range } 24-63, \text { "mostly middle-aged"); } \\
\text { majority Caucasian ( } 61 \% \text { Caucasian, } 33 \% \\
\text { African American, 6\% other); } 48 \% \text { employed, } \\
48 \% \text { unemployed; mean monthly income } \\
\text { \$1023 (sd } 699) \text {; all men who have sex with } \\
\text { men; 33\% cohabiting, } 19 \% \text { relationship but } \\
\text { living apart, } 48 \% \text { "did not have a primary part- } \\
\text { ner"; mean } 4.8 \text { sexual partners in past year (sd } \\
\text { 10.9). }\end{array}$ \\
\hline $\begin{array}{l}\text { Wallace [81] } \\
\text { USA }\end{array}$ & $\begin{array}{l}\text { Psychosocial needs of men with } \\
\text { prostate cancer }\end{array}$ & various & cancer - prostate & FG 16 men (2 groups) & $\begin{array}{l}\text { descriptive/ } \\
\text { interpretive }\end{array}$ & $\begin{array}{l}\text { mean } 4.3 \text { yrs since diagnosis (range } 6 \\
\text { months- } 12 \text { yrs); mean age } 66.8 \text { yrs (range } 49- \\
81 \text { ); majority Caucasian ( } 1 \text { African American, } 1 \\
\text { other); range of education ( } 8 \text { high school, } 5 \\
\text { college, } 3 \text { graduate school); annual income } \\
\text { ranged } \$ 20,000-\$ 100,000 ; \text { majority married } \\
\text { (15 married, } 1 \text { divorced). }\end{array}$ \\
\hline
\end{tabular}


involved sharing of experiences. There was little awareness of the exercise, pain management, and educational options available". (second-order construct, emphasis added) [23]

Seeking and accepting any type of SMS can pose threats to the identity of men who align themselves with masculine ideals embodied by independence and selfsufficiency. In these cases, men may feel the need to justify or legitimise their involvement in order to preserve their identity as a man [82]. Several studies have reported the instrumental role of family or friends in prompting men's engagement with SMS; for example, in identifying a need for support, accompanying men when attending activities, or helping to access and navigate information [43,52,55,58,60,63,76,81]. Being able to 'give back' when engaging in SMS can be an important way for men to legitimise their involvement and lessen perceptions of their own need or vulnerability.

"Perhaps once men establish that their primary concern is to offer help to others it may became less problematic to admit to benefiting from the group themselves". (second-order construct) [82]

'Giving back' via relationships with peers or through taking on leadership roles such as committee membership, can be important for male identity and self-esteem $[53,63,82,83]$. Adopting a 'business-like' approach can be particularly appealing to some [63], perhaps reflecting the ways in which LTCs can challenge men's identities as men; for example, through loss of identity through loss of work $[23,61]$.

"....in addition to meeting the information needs of newly diagnosed men, the group meetings needed to offer "new" information to maintain the interest of long-term members, because their commitment to the group was often premised on continuing to learn, as well as "giving back" to newly diagnosed men". (second-order construct) [83]

\section{Trusted environments}

Fostering a trusted environment where men feel comfortable and able to participate in support activities is critical for accessibility and acceptability of SMS, especially where participation has the potential to make men feel vulnerable or lacking in confidence. The clearest example of this is when interventions or group-based activities involve the discussion of 'taboo' topics - such as mental health, sexual function, and/or emotional expression - which can challenge masculine ideals and behavioural expectations [42,71,72]. In face-to-face support activities, group dynamics can promote the discussion of 'taboo topics'. In prostate cancer support groups, for example, rational and objective discussions on functionality, rather than feelings, can legitimise a supportive and collective problem-solving group dynamic that encourages men to 'open up' about potentially difficult topics, such as erectile dysfunction [72]. This way of talking can also allow men to 'open up' to different ways of thinking about activities not usually constructed as fitting with stereotypical masculine roles such as cooking or abstaining from alcohol consumption [71,72].

"... being chauvinistic males we tend to keep it to ourselves ... But when I'm amongst people like this I feel safe and confident". (first-order construct) [48]

Group dynamics can also work to stifle emotional expression and, in some cases, a lack of emotional sharing may in fact reflect opportunities to 'share' are constrained by group processes rather than an unwillingness on the men's behalf [52]. Practises such as topic-turning by facilitators can serve to discourage or "squelch" emotional talk $[42,47]$. Thus, although a focus on problemsolving and the practical aspects of potentially emotive topics can represent a positive way to facilitate the discussion of potentially taboo topics among men [72], it can also be a practice employed to avoid or curtail emotional talk and listening to underlying concerns and experiences [42,71].

"Jim was visibly disturbed by the effect of the hormone on his body, but rather than address that concern, the group moved into a discussion of financial matters, an instrumental issue". (secondorder construct) [42]

Both lay and health professional facilitators of SMS are instrumental in fostering a trusted environment for men. Healthcare professionals can play a key role in either enabling or inhibiting access and this may be particularly important in mental health conditions, where establishing a one-to-one relationship with a facilitator can be crucial before men feel willing and able to attend support groups [53,57]. In multi-component lifestyle interventions, especially those involving physical activity, supportive and positive professional facilitators have a key role in motivating men to adopt behaviour changes and supervising activities where men lack confidence $[41,43,48,59,69]$. Allowing men some control over their level of involvement in interventions involving both physical activity $[41,74]$ or discussion-based support $[72,75]$ can also improve acceptability. For example, a study of prostate cancer support groups noted the value men placed on being "allowed" to listen without feeling an expectation to talk. 
"Men who did not want to talk could listen without worrying about being put on the spot to say something, whereas others could comfortably share questions and comments from within the group". (second-order construct) [72]

"I finally screwed up the courage to say something ... I looked around expecting people to look shocked or disapproving. ... People just nodded ... and reacted like it was no big deal. After that, I was able to talk more openly ..." (first-order construct) [75]

Men also value having control over their level of involvement in online forums, where some may prefer to 'lurk' rather than (or prior to) posting $[49,62,78]$. 'Lurking' can be a necessary step for some men in the 'opening up' process; enabling those who may not feel able to ask questions to gain some benefit from the interactions of those who are more active [49]. 'Lurking' may also reflect men's desire to learn the rules of talk before actively participating $[62,78]$ in order to become "comfortable in knowing 'how to' participate" [78].

\section{Value of peers}

Interaction with peers is widely valued by men across a range of SMS activities. Peers are generally seen as those who are "roughly in the same boat" [50]. Differences in some social characteristics (such as age, ethnicity, class/ economic background) are often transcended by a shared experience of a particular health issue and by gender [41,51]. An assumed empathy based on experiences that are sufficiently similar can allow men a 'break' from their illness (and disrupted identities) and the ability to fall back on a degree of intuition in understanding how others feel $[66,79]$. This can mean that less needs to be explicitly voiced $[41,51]$.

"We don't need to convolute things by asking how someone feels today because we can see it ... We understand just when to laugh and sometimes when we should be quiet". (first-order construct) [41]

For many men with LTCs, the peers they encounter through SMS activities (either face-to-face or online) provide a welcome opportunity to experience a sense of belonging and normality $[53,55,62,72,78]$. The validation that, as men with a chronic health condition, they could regain a male 'insider' rather than 'outsider' status appears to be important across several different health conditions (e.g. cardiac conditions [43] prostate cancer [81]).

"you can't separate support from understanding. ... there's nothing more supportive to me than when someone says, "Yeah, I know" or "I understand" or "it's happened to me" ... that commonality" (firstorder construct) [79]

"I felt part of a ... team, and really wanted to be there for other people no matter what condition I was in".

(first-order construct) [50]

A strong peer-group identity can encourage health behaviour change through a sense of team spirit, camaraderie, social commitment and obligation [41,43,48,59]. Peers can also offer men a "living example" [72] of hope, optimism and inspiration that can help individuals achieve a sense of perspective, and also act as a 'credible source' from whom they can garner information and learn about self-management [53,59,66,80]. Learning from peers by sharing self-management tips and strategies [59] or reading accounts of 'survivor stories' $[58,70]$ may be more acceptable than learning from health professionals because relationships are more equal and there is less of a feeling of being "preached at" $[66,80]$.

In some cases, men may value attending support interventions with those who are peers across 'several layers'. In this way, being in the 'same boat' requires having multiple things in common as well as shared illness experience (for example, age, gender, sexuality or culture); something particularly evident among men living with conditions perceived to be 'stigmatised', such as depression and HIV/AIDS $[51,53,68,80]$. Thus, for some men, peers and trusted environments are about taking part in activities with other men in 'male-only' spaces, but for others it is not. For example, prostate cancer is often described as a 'couple's disease' and face-to-face support groups and online discussion forums can sometimes be made more acceptable with the participation of female partners $[49,63,78]$. Regardless, support provided from peers is seen as distinct from the support received from friends and family $[46,65,72,75,79]$. Being away from family and friends can allow men to share experiences without fear of ramifications and the related desire to protect friends and family from the 'burden' of their own condition and associated needs [79].

“... you have also created an enormous burden on others ... I belong to the support group, because ... we all understand each other. There are a few people there who are very important to me. They're not friends. ... there's that distance. We just get together to unburden ..."(first-order construct) [46]

\section{Becoming an expert}

Many men place a high value on receiving health information and education in order to develop their capacity to manage and 'become an expert' in their condition [42,44,45,47,49,55,58,62,63,70,72,73,76,78]. Developing 
knowledge and expertise in SMS can also provide men with opportunities to 'give back' to others as a layeducator; a role that can act as a key motivator for (ongoing) use of SMS, as described above, and have associated benefits for men's self-identity and selfesteem [47-49,55,66,72,75,78,79].

"People [men] are hungry for information, what is the latest in research ... People are just dying to get their hands on the latest information". (first-order construct) [65]

"Through this process of giving support to others, these men experienced an empowering sense of meaning and accomplishment" (second-order construct) [75]

Developing self-management expertise can extend to gaining skills in navigating health services, facilitating patient-health professional interactions, and attaining partnership in decision-making [55,73]. Knowledge can allow men to gain "currency" and "power" [55], and lead to them becoming informed consumers who can 'shop around' for healthcare providers and treatments.

"Consumer discourses and strategies to contest power relations with health care professionals underpinned many men's search for prostate cancer information and their commitment to assisting other men".

(second-order construct) [73]

Opportunities to build confidence and expertise in communicating with care providers can be an attractive component of SMS; for example, through face-to-face question-answer sessions or online interactions with health professionals $[42,48,73,78]$. Such involvement with care providers can be particularly valued when men feel dissatisfied with clinical interactions; for example, due to lack of time with health professionals and lack of power and partnership [48,52].

"[Knowledge] not only gives you the information to feel comfortable, but also gives you the information and a tool to check the physician. Not just his reputation but also the information he is giving you". (first-order construct) [55]

Using and sharing medical terminology and technical information can be particularly attractive to men [42,73]. That said, not all welcome the opportunity to act in the role of 'consumer' of health services, instead preferring to devolve decision-making to health professionals as experts who "know their stuff" $[49,58]$.
"Imagine being in a fast flowing river and the guy on the bank has got half a dozen different aids to help you and he's shouting to you 'which one do you want?'. You know, I don't care which one it is as long as...you know which one to throw" (first-order construct) [58])

Overly complex or technical information can, however, also act as a barrier to learning, provoke anxiety, and overwhelm [76]. Allowing men the freedom to learn in their own way without feeling the threat of being derided for their lack of knowledge about specific health and illness issues can improve accessibility. Complex content, style, or language can reduce the accessibility of information [73] and limit patient empowerment [49]. Information that is presented in 'everyday language', can be integrated with daily life, and that is tailored to demographic characteristics that men can relate to is particularly appealing for some [67,70]. For example, strategies or usable information on "the why's and how you do it" [70] is preferable to standardized or general health messages that can be seen as lacking "respect for the individual and his context" [56]. Significant others can also play a key role for men in obtaining information and help protect them from feeling overwhelmed by information; for example, using "lay referral networks" or "internet-savvy" friends and family, to navigate and "filter" information resources $[55,58,76]$.

\section{Discussion}

Despite growing calls for tailored and targeted health interventions to be delivered to men [32], the existing evidence-base has not yet provided a strong steer on how best to design and deliver services to address men's distinct needs [84]. The systematic review and metasynthesis undertaken here points toward some key considerations in relation to the content and process of SMS that may be important in helping to optimise interventions to be more accessible and acceptable to men with LTCs.

Recent evidence has shown that the accessibility and acceptability of behaviour change interventions can be improved when the context, content, and delivery style of interventions are tailored to be in alignment with valued aspects of men's identities [31,85-87]. A crosscutting theme in our synthesis was the tensions that men experienced between a perceived need to fulfil roles and obligations linked to their identities as men, and acceptance of living with and needing help to manage a LTC that could potentially threaten those identities. It is clear that the physical and mental impacts of living with a LTC can pose significant challenges to men's masculinity; a theme that has been recognised elsewhere as a "loss of self" [88] as men try to renegotiate and recapture 
aspects of masculine identity they feel have been lost through chronic illness $[89,90]$.

Our findings are in line with a recent broader review of the role and effectiveness of SMS in LTCs [91] which points toward the 'biographical disruption' LTCs can have on an individual's 'normal' life, and the need to reconstruct one's identity by adjusting to the physical, emotional, and societal implications of illness [92,93]. Our synthesis places this 'disruption' in the context of men's gender identity and, in doing so, indicates that SMS is most likely to be successful in engaging men when working with, not against, cultural ideals of masculinity. In other words, as Hunt and colleagues have previously stated, support interventions need to engage men without being an anathema to valued aspects of their identities [31].

Here, our findings highlight the potential importance of positioning and marketing SMS interventions in ways that pre-empt or overcome potential threats to masculine identities; whilst being mindful that men are not a homogenous group and that SMS needs and preferences will likely vary amongst men and may change with the trajectory of their illness. Strategies such as demonstrating a clear purpose to an intervention and offering opportunities to maintain control and/or 'give back' are likely to be beneficial, although such approaches should address changing needs and recognise different purpose in initial and ongoing use [91]. This links to the need for some men to tackle emotional issues 'sideways on', as a 'by-product' of other shared activities. Intimacy and emotional sharing may become hampered if made too explicit a (initial) goal of support activities. Crucially, our synthesis suggests that 'trusted environments' afforded by online communities and peer support groups can help men to overcome cultural expectations of masculinity and enable them to 'open up' emotionally.

Peer support can offer men a sense of belonging and community and was widely reported to help men adjust and come to terms with their health problems. Consistent with a recent review of weight-management programmes in men with obesity [87], being able to identify with the illness experience of others to some degree appears to be of foremost importance in determining who is a 'peer'. However, aligned with the findings of the Football Fans in Training (FFIT) study, which attracted 'like-minded' and 'like-bodied' men who shared an interest in football and had similar physiques and levels of fitness ('people like them') [85], our synthesis highlighted that having multiple things in common with peers (including gender) may improve accessibility and acceptability of SMS for some men. Being around 'people like them' may be particularly important for men when they have a chronic problem which makes them feel that they 'stand out from the herd' [89]; distinct from other men and perhaps unable to 'perform' their masculinity in different contexts in ways which they have been accustomed to at other times in their adult life.

\section{Strengths and limitations of the review}

The difficulty in systematically identifying qualitative studies in research databases is well recognised [36]. This is further accentuated in qualitative studies of selfmanagement, since they are frequently not labelled as SMS, but rather are often simply referred as support groups or educational programmes. A strength of this review was the thoroughness of our search, which involved the title/abstract screening of 6330 unique records and offers a comprehensive picture of the available qualitative research. The approach adopted in the metaethnography did not preclude synthesis across studies of different types of intervention or support activities, but the limited amount of data and analysis reported in papers meant it was not possible to unpick the accessibility and acceptability of particular types compared with others. In addition, the synthesis is likely to have been heavily influenced by the literature on face-to-face group-based support interventions as this was the most common type of intervention/activity represented in the extant research.

Whilst the influence of culturally-dominant (hegemonic) masculine ideals was a cross-cutting theme in our synthesis, the findings need to be interpreted with caution. A body of recent work has begun to question the simplistic link between constructions of hegemonic masculinity and men's health-care practices [94]. Evidence of the fluid and contextually-dependent nature of gender in the wider body of men's health literature $[95,96]$ suggests that the studies included in our synthesis may not adequately capture the complexity of how masculinities intersect with men's health behaviour. There is unlikely to be a 'one-size-fits-all' approach to gender-sensitising SMS for men. Indeed, the metaethnography suggested that men and women may both benefit from a particular intervention components/types (e.g. peer support, information sharing) if they have similar personal preferences and/or a shared illness experience. Although the review findings point toward some key considerations that may be important in helping to optimise interventions to be more accessible and acceptable to men, clearly, gender is not a 'stand-alone' variable that determines access and engagement. The factors discussed here in relation to the content and processes of designing and delivering SMS may help to improve acceptability and accessibility in certain subgroups of men (e.g. those who adhere to hegemonic masculine ideals) but not others. Further research is required to explore the complexity of the relationships 
between gender and other factors known to influence access and engagement to interventions.

\section{Implications for future research, policy and practice}

Person-centred care is at the heart of a whole system approach to LTC management [97]. In order to make SMS person-centred, findings from this review echo recommendations for interventions to be tailored to individual preferences and lifestyles [91,98]; for men living with LTCs, this is likely to involve consideration of their identity as a man. Health professionals and service commissioners might usefully consult with male service users about how to make existing support interventions more appealing to, and congruent with, key aspects of their identities.

Gender-sensitising SMS in context (e.g. delivered in a trusted environment among peers), content (e.g. actionorientated), delivery style (e.g. a problem-solving/practical approach) and marketing (e.g. emphasis on purpose/ tangible results) may yield benefits. However, health professionals need to recognise that men are not a homogenous group and that there is unlikely to be a 'one-size-fits-all' approach that meets the requirements of all men. Men may be willing to accept different types of interventions or activities once they feel they are in a trusted environment with peers, including ones which at the outset may have appeared to present some challenge to aspects of male identity.

Further primary research is required to examine which models of service delivery are most effective and costeffective in providing SMS to men (and women). The complex and contextually-dependent nature of men's engagement with self-management support interventions highlighted in this review suggests that a study drawing on realist principles [99] might be one method of analysis which might have utility. Parallel primary qualitative research is also needed to develop our understanding of what makes interventions, and their 'active ingredients', accessible and acceptable for men with LTCs. In particular, the self-management experiences and perceptions of men of differing age, ethnicity and socioeconomic background need to be considered. Men are a heterogeneous group, yet consideration of how these factors intersect with men's gender identities has rarely been a focus in previous qualitative research.

\section{Conclusions}

This qualitative systematic review and meta-synthesis aimed to determine whether SMS is accessible and acceptable to men, and explore what may act as facilitators and barriers to access of interventions and support activities. We identified four key constructs associated with men's experiences of, and perceptions towards, SMS: 1) need for purpose; 2) trusted environments; 3) value of peers; and 4) becoming an expert. The constructs suggest that men may find SMS more accessible and acceptable when it has a clear purpose that addresses an unmet need; is delivered in an environment that offers a sense of shared understanding and 'normality'; involves and/or is facilitated by men with a shared illness experience; and offers personally meaningful health information and practical strategies that can be integrated into daily life.

In order to overcome barriers to access and fully engage with interventions, men may need to feel that participating in SMS does not challenge valued aspects of their identities, particularly masculine ideals associated with independence, stoicism, and control. This is an important consideration for the design and delivery of future SMS interventions if they are to work to support the growing number of men living with LTCs.

\section{Additional file}

Additional file 1: Second-order findings and corresponding third-

order constructs of each study.

\section{Abbreviations}

LTC: Long term condition; SMS: Self management support; PPI: Public and patient involvement.

\section{Competing interests}

The authors declare that they have no competing interests. All authors were funded for this project (and manuscript preparation) by the National Institute for Health Research Health Services and Delivery Research Programme (project number 12/5001/14). Views expressed are those of the authors and do not necessarily reflect those of the HS\&DR programme, NIHR, NHS or Department of Health.

\section{Authors' contributions}

PG managed the project and had primary responsibility for writing the manuscript. ZD led the review and analysis, and contributed to writing the manuscript. LK made contributions to the design and conduct of the study, the analysis, and contributed to the writing of the manuscript. CB made contributions to the design and conduct of the study, the analysis, and contributed to the writing of the manuscript. KM made contributions to the design and conduct of the study, the analysis, and contributed to the writing of the manuscript. $\mathrm{KH}$ made contributions to the design and conduct of the study, the analysis, and contributed to the writing of the manuscript. PB made contributions to the design and conduct of the study, the analysis, and contributed to the writing of the manuscript. SG made contributions to the design and conduct of the study, the analysis, and contributed to the writing of the manuscript.GR made contributions to the design and conduct of the study, the analysis, and contributed to the writing of the manuscript. All authors read and approved the final manuscript.

\section{Acknowledgements}

The authors would like to thank Kath Wright and the staff at CRD, University of York, for their assistance with the literature searches, and Dr. Rosaleen O'Brien, Glasgow Caledonian University, for her contributions to the study design. We would also like to sincerely thank the five men who were involved in the PPI group.

This project was funded by the National Institute for Health Research Health Services and Delivery Research Programme (project number 12/5001/14). Views expressed are those of the authors and do not necessarily reflect those of the HS\&DR programme, NIHR, NHS or Department of Health. 


\section{Author details}

${ }^{1}$ Department of Health Sciences, University of York, York YO10 5DD, UK. ${ }^{2}$ School of Healthcare, University of Leeds, Leeds LS2 9JT, UK. ${ }^{3}$ School of Health and Life Sciences/Institute for Applied Health Research, Glasgow Caledonian University, Glasgow G4 0BA, UK. ${ }^{4} \mathrm{NIHR}$ School for Primary Care Research, Manchester Academic Health Science Centre, University of Manchester, Manchester, UK. ${ }^{5} \mathrm{MRC} / \mathrm{CSO}$ Social and Public Health Sciences Unit, University of Glasgow, Glasgow G12 8QQ, UK. ${ }^{6}$ Centre for Health Economics, University of York, York YO10 5DD, UK.

Received: 19 September 2014 Accepted: 18 November 2014 Published: 27 November 2014

\section{References}

1. Department of Health: Improving Chronic Disease Management. London: Department of Health; 2004.

2. Department of Health: Long Term Conditions Compendium of Information, Third Edition edn. London: Department of Health; 2012.

3. Department of Health: Self-Care: A Real Choice. London: Department of Health; 2005.

4. Kennedy A, Bower P, Reeves D, Blakeman T, Bowen R, Chew-Graham C, Eden M, Fullwood C, Gaffney H, Gardner C: Implementation of self management support for long term conditions in routine primary care settings: cluster randomised controlled trial. BMJ 2013, 346:f2882.

5. Department of Health: Supporting People with Long Term Conditions: an NHS and Social Care Model to Support Local Innovation and Integration. London: Department of Health; 2005.

6. Adams K, Greiner A, Corrigan J: Report of a summit, The 1st annual crossing the quality chasm summit: a focus on communities; 2004:6-7.

7. DAFNE Study Group: Training in flexible, intensive insulin management to enable dietary freedom in people with type 1 diabetes: dose adjustment for normal eating (DAFNE) randomised controlled trial. BMJ 2002, 325(7367):746.

8. Davies MJ, Heller S, Skinner T, Campbell M, Carey M, Cradock S, Dallosso H, Daly $H$, Doherty $Y$, Eaton S: Effectiveness of the diabetes education and self management for ongoing and newly diagnosed (DESMOND) programme for people with newly diagnosed type 2 diabetes: cluster randomised controlled trial. BMJ 2008, 336(7642):491-495.

9. Barlow J, Singh D, Bayer S, Curry R: A systematic review of the benefits of home telecare for frail elderly people and those with long-term conditions. J Telemed Telecare 2007, 13(4):172-179.

10. Kennedy A, Reeves D, Bower P, Lee V, Middleton E, Richardson G, Gardner C, Gately C, Rogers A: The effectiveness and cost effectiveness of a national lay-led self care support programme for patients with long-term conditions: a pragmatic randomised controlled trial. J Epidemiol Community Health 2007, 61(3):254-261.

11. Lorig KR, Sobel DS, Stewart AL, Brown BW Jr, Bandura A, Ritter P, Gonzalez VM, Laurent DD, Holman HR: Evidence suggesting that a chronic disease self-management program can improve health status while reducing hospitalization: a randomized trial. Med Care 1999, 37(1):5-14.

12. Deakin TA, McShane CE, Cade JE, Williams R: Group based training for self-management strategies in people with type 2 diabetes mellitus. Cochrane Database Syst Rev 2005, 18(2):CD003417.

13. Duncan E, Best C, Hagen S: Shared decision making interventions for people with mental health conditions. Cochrane Database Syst Rev 2010, 20(1):CD007297.

14. Foster G, Taylor S, Eldridge S, Ramsay J, Griffiths C: Self-management education programmes by lay leaders for people with chronic conditions. Cochrane Database Syst Rev 2007, 17(4):CD005108.

15. Haynes RB, Ackloo E, Sahota N, McDonald Heather P, Yao X: Interventions for enhancing medication adherence. Cochrane Database Syst Rev 2008, 16(2):CD000011.

16. Phillips J: Self Care Reduces Costs and Improves Health - The Evidence. London: Expert Patients Programme; 2010.

17. Panagioti M, Richardson G, Small N, Murray E, Rogers A, Kennedy A Newman S, Bower P: Self-management support interventions to reduce health care utilisation without compromising outcomes: a systematic review and meta-analysis. BMC Health Serv Res 2014, 14:356.

18. Furler J, Harris M, Rogers $A$ : Equity and long-term condition self-management. Chronic Illn 2011, 7(1):3-5.
19. Chodosh J, Morton SC, Mojica W, Maglione M, Suttorp MJ, Hilton L, Rhodes S, Shekelle P: Meta-analysis: chronic disease self-management programs for older adults. Ann Intern Med 2005, 143(6):427-438.

20. Taylor D, Bury M: Chronic illness, expert patients and care transition. Sociol Health IIIn 2007, 29(1):27-45.

21. Lorig KR, Ritter P, Stewart AL, Sobel DS, Brown W, Bandura A, Gonzalez VM Laurent DD, Holman HR: Chronic disease self-management program: 2-year health status and health care utilization outcomes. Med Care 2001, 39(11):1217.

22. Bury M, Newbould J, Taylor D: A rapid Review of the Current state of Knowledge Regarding Lay Led self Management of Chronic illness: Evidence Review. London: National Institute for Health and Clinical Excellence; 2005.

23. Gibbs L: Identifying work as a barrier to men's access to chronic illness (arthritis) self-management programs. Int J Men's Health 2007, 6(2):143-155.

24. Banks I: No man's land: men, illness and the NHS. BMJ 2001, 323:1058-1060.

25. European Commission: The state of men's health in Europe report. 2011. http://ec.europa.eu/health/population_groups/docs/men_health_ report_en.pdf.

26. Galdas PM, Cheater F, Marshall P: Men and health help-seeking behaviour: literature review. J Adv Nurs 2005, 49(6):616-623.

27. Courtenay $\mathrm{WH}$ : Key determinants of the health and well-being of men and boys. Int J Men's Health 2003, 2(1):1-30.

28. O'Brien R, Hunt K, Hart G: 'It's caveman stuff, but that is to a certain extent how guys still operate': men's accounts of masculinity and help-seeking. Soc Sci Med 2005, 61(3):503-516.

29. McCartney G, Mahmood L, Leyland AH, Batty GD, Hunt K: Contribution of smoking-related and alcohol-related deaths to the gender gap in mortality: evidence from 30 European countries. Tob Control 2011, 20(2):166-168

30. Galdas PM: Man up: engaging men in primary care. Practice Nursing, 23(1):10-13

31. Hunt K, McCann C, Gray CM, Mutrie N, Wyke S: "You've got to walk before you run": Positive evaluations of a walking program as part of a gendersensitized, weight-management program delivered to men through professional football clubs. Health Psychol 2013, 32(1):57.

32. White A, McKee M, Richardson N, Visser R, Madsen SA, Sousa BC, Hogston R, Zatoński W, Makara P: Europe's men need their own health strategy. BMJ 2011, 343:d7397

33. Wilkins D, Payne S, Granville G, Branney P: The Gender and Access to Health Services Study: Final Report. London: Department of Health; 2008.

34. Noblit GW, Hare RD: Meta-ethnography: Synthesizing qualitative studies, Volume 11. London: Sage Publications, Inc; 1988

35. Campbell R, Pound P, Morgan M, Daker-White G, Britten N, Pill R, Yardley L, Pope C, Donovan J: Evaluating meta-ethnography: Systematic analysis and synthesis of qualitative research. Health Technol Assess 2011, 15(43):1-164.

36. Flemming K, Briggs M: Electronic searching to locate qualitative research: evaluation of three strategies. J Adv Nurs 2007, 57(1):95-100.

37. Shaw RL, Booth A, Sutton AJ, Miller T, Smith JA, Young B, Jones DR, Dixon-Woods M: Finding qualitative research: An evaluation of search strategies. BMC Med Res Methodol 2004, 4(5):5.

38. Critical Appraisal Skills Program: Critical Appraisal Skills Programme (CASP) Qualitative Research Checklist 31.05.13. 10 questions to help you make sense of qualitative research. CASP; 2013. http://media.wix.com/ugd/ dded87_951541699e9edc71ce66c9bac4734c69.pdf.

39. Atkins S, Lewin S, Smith H, Engel M, Fretheim A, Volmink J: Conducting a meta-ethnography of qualitative literature: Lessons learnt. BMC Med Res Methodol 2008, 8(21):10.

40. Schutz A: Collected papers, Volume 1. The Hague: Martinus Nijhoff; 1971.

41. Adamsen L, Rasmussen JM, Pedersen LS: Brothers in arms': how men with cancer experience a sense of comradeship through group intervention which combines physical activity with information relay. J Clin Nurs 2001, 10(4):528-537.

42. Arrington Ml, Grant $\mathrm{CH}$, Vanderford ML: Man to man and side by side, they cope with prostate cancer: self-help and social support. J Psychosoc Oncol 2005, 23(4):81-102.

43. Baird KK, Pierce LL: Adherence to cardiac therapy for men with coronary artery disease. Rehabil Nurs J 2001, 26(6):233-237.

44. Barlow J, Edwards R, Turner A: The experience of attending a lay-led, chronic disease self-management programme from the perspective of participants with multiple sclerosis. Psychol Health 2009, 24(10):1167-1180. 
45. Barlow JH, Turner AP, Gilchrist M: A randomised controlled trial of lay-led self-management for myocardial infarction patients who have completed cardiac rehabilitation. Eur J Cardiovasc Nurs 2009, 8(4):293-301.

46. Bedell G: Daily life for eight urban gay men with HIV/AIDS. Am J Occup Ther 2000, 54(2):197-206.

47. Bell K, Lee J, Foran S, Kwong S, Christopherson J: Is there an "ideal cancer" support group? Key findings from a qualitative study of three groups. J Psychosoc Oncol 2010, 28(4):432-449.

48. Bourke L, Sohanpal R, Nanton V, Crank H, Rosario DJ, Saxton JM: A qualitative study evaluating experiences of a lifestyle intervention in men with prostate cancer undergoing androgen suppression therapy. Trials [Electronic Resource] 2012, 13:208.

49. Broom A: Virtually he@lthy: the impact of internet use on disease experience and the doctor-patient relationship. Qual Health Res 2005, 15(3):325-345

50. Chambers SK, Foley E, Galt E, Ferguson M, Clutton S: Mindfulness groups for men with advanced prostate cancer: a pilot study to assess feasibility and effectiveness and the role of peer support. Support Care Cancer 2012, 20(6):1183-1192.

51. Chenard C: The impact of stigma on the self-care behaviors of HIV-positive gay men striving for normalcy. J Assoc Nurses Aids Care 2007, 18(3):23-32.

52. Corboy D, McDonald J, McLaren S: Barriers to Accessing Psychosocial Support Services among Men with Cancer Living in Rural Australia: Perceptions of Men and Health Professionals. Int J Men's Health 2011, 10(2):163-183.

53. Cramer H, Horwood J, Payne S, Araya R, Lester H, Salisbury C: Do depressed and anxious men do groups? What works and what are the barriers to help seeking? Prim Health Care Res Dev 2014, 15(3):287-301.

54. Dickerson SS, Boehmke M, Ogle C, Brown JK: Seeking and Managing Hope: Patients' Experiences Using the Internet for Cancer Care. Oncology Nursing Forum 2006, 33(1):E1-E10.

55. Dickerson SS, Reinhart A, Boemhke M, Akhu-Zaheya L: Cancer as a problem to be solved: internet use and provider communication by men with cancer. Cin Comput Inform Nurs 2011, 29(7):388-395.

56. Eldh AC, Ehnfors M, Ekman I: The meaning of patient participation for patients and nurses at a nurse-led clinic for chronic heart failure. Eur J Cardiovasc Nurs 2006, 5:45-53.

57. Emslie C, Ridge D, Ziebland S, Hunt K: Exploring men's and women's experiences of depression and engagement with health professionals: more similarities than differences? A qualitative interview study. BMC Fam Pract 2007, 8:43.

58. Evans M, Shaw A, Thompson EA, Falk S, Turton P, Thompson T, Sharp D: Decisions to use complementary and alternative medicine (CAM) by male cancer patients: information-seeking roles and types of evidence used. BMC Complement Altern Med 2007, 7:25

59. Ferrand C, Perrin C, Nasarre S: Motives for regular physical activity in women and men: a qualitative study in French adults with type 2 diabetes, belonging to a patients' association. Health Soc Care Community 2008, 16(5):511-520.

60. Galdas PM, Oliffe JL, Wong ST, Ratner PA, Johnson JL, Kelly MT: Canadian Punjabi Sikh men's experiences of lifestyle changes following myocardial infarction: cultural connections. Ethnicity Health 2012, 17(3):253-266.

61. Gibbs L: Applications of masculinity theories in a chronic illness context. Int J Men's Health 2005, 4(3):287-300.

62. Gooden RJ, Winefield HR: Breast and prostate cancer online discussion boards: a thematic analysis of gender differences and similarities. $J$ Health Psychol 2007, 12(1):103-114.

63. Gray R, Fitch M, Davis C, Phillips C: Breast cancer and prostate cancer self-help groups: Reflections on differences. Psycho-Oncology 1996, 5(2):137-142.

64. Gray R, Fitch M, Davis C, Phillips C: A qualitative study of breast cancer self-help groups. Psycho-Oncology 1997, 6:279-289.

65. Gray RE, Fitch M, Davis C, Phillips C: Interviews with men with prostate cancer about their self-help group experience. J Palliat Care 1997, 13(1):15-21.

66. Harris $G E$, Alderson $K$ : An investigation of gay men's experiences with HIV counselling and peer support services. Can J Community Ment Health 2007, 26(1):129-142.

67. Iredale R, Williams B, Brain K, France E, Gray J: The information needs of men with breast cancer. Br J Nurs 2007, 16(9):540-544.

68. Kendall J: Promoting wellness in HIV-support groups. J Assoc Nurses AIDS Care 1992, 3(1):28-38.
69. Kronenwetter C, Weidner G, Pettengill E, Marlin R, Crutchfield L, McCormac $P$, Raisin CJ, Ornish D: A qualitative analysis of interviews of men with early stage prostate cancer: the Prostate Cancer Lifestyle Trial. Cancer Nurs 2005, 28(2):99-107.

70. Martin F, Turner A, Bourne C, Batehup L: Development and qualitative evaluation of a self-management workshop for testicular cancer survivor-initiated follow-up. Oncol Nurs Forum 2013, 40(1):E14-E23.

71. Mfecane S: Negotiating therapeutic citizenship and notions of masculinity in a South African village. Ajar-Afr J Aids Res 2011, 10(2):129-138.

72. Oliffe $J$, Gerbrandt JS, Bottorff $J$, Hislop TG: Health promotion and illness demotion at prostate cancer support groups. Health Promot Pract 2010, 11(4):562-571.

73. Oliffe JL, Bottorff JL, McKenzie MM, Hislop TG, Gerbrandt JS, Oglov V: Prostate cancer support groups, health literacy and consumerism: are community-based volunteers re-defining older men's health? Health 2011, 15(6):555-570.

74. Ramachandra P, Booth S, Pieters T, Vrotsou K, Huppert FA: A brief selfadministered psychological intervention to improve well-being in patients with cancer: results from a feasibility study. Psycho-Oncology 2009, 18(12):1323-1326.

75. Sandstrom KL: Searching for information, understanding, and self-value: the utilization of peer support groups by gay men with HIV/AIDS. SOC Work Health Care 1996, 23(4):51-74.

76. Seale C, Ziebland S, Charteris-Black J: Gender, cancer experience and internet use: a comparative keyword analysis of interviews and online cancer support groups. Soc Sci Med 2006, 62(10):2577-2590.

77. Smith RL, Crane LA, Byers T, Nelson-Marten P: An evaluation of the Man to Man self-help group in Colorado and Utah. Cancer Practice 2002, 10(5):234-239.

78. Sullivan CF: Gendered Cybersupport: A Thematic Analysis of Two Online Cancer Support Groups. J Health Psychol 2003, 8(1):83-103.

79. Trapp SK, Woods JD, Grove A, Stern M: Male coping processes as demonstrated in the context of a cancer-related social support group. Support Care Cancer 2013, 21(2):619-627.

80. Vanable PA, Carey MP, Brown JL, Littlewood RA, Bostwick R, Blair D: What HIV-positive MSM want from sexual risk reduction interventions: Findings from a qualitative study. AIDS Behav 2012, 16(3):554-563.

81. Wallace $M$, Storms $S$ : The needs of men with prostate cancer: results of a focus group study. App/ Nurs Res 2007, 20(4):181-187.

82. Seymour-Smith S: 'Blokes don't like that sort of thing': men's negotiation of a 'troubled' self-help group identity. J Health Psychol 2008, 13(6):785-797.

83. Oliffe $J$, Halpin M, Bottorff $J$, Hislop TG, McKenzie M, Mroz L: How prostate cancer support groups do and do not survive: British Columbian perspectives. Am J Mens Health 2008, 2(2):143-155.

84. Douglas FC, Greener J, Van Teijlingen E, Ludbrook A: Services just for men? Insights from a national study of the well men services pilots. BMC Public Health 2013, 13(1):425.

85. Hunt K, Gray CM, Maclean A, Smillie S, Bunn C, Wyke S: Do weight management programmes delivered at professional football clubs attract and engage high risk men? A mixed-methods study. BMC Public Health 2014, 14(1):50.

86. Hunt K, Wyke S, Gray CM, Anderson AS, Brady A, Bunn C, Donnan PT, Fenwick E, Grieve E, Leishman J: A gender-sensitised weight loss and healthy living programme for overweight and obese men delivered by Scottish Premier League football clubs (FFIT): a pragmatic randomised controlled trial. Lancet 2014, 383(9924):1211-1221.

87. Robertson C, Archibald D, Avenell A, Douglas F, van Teijlingen E, Boyers D, Stewart F, Boachie C, Fioratou E, Wilkins D, Street T, Carroll P, Fowler C: Systematic reviews and integrated report on the quantitative, qualitative and economic evidence base for the management of obesity in men. Health Technol Assess 2014, 18(35):v-vi, xxiii-xxix, 1-424.

88. Charmaz K: Loss of self: a fundamental form of suffering in the chronically ill. Sociology Health IIIn 1983, 5(2):168-195.

89. O'Brien R, Hart GJ, Hunt K: Standing out from the herd: men renegotiating masculinity in relation to their experience of illness. Int J Men's Health 2007, 6(3):178-200.

90. Clarke LH, Bennett E: 'You learn to live with all the things that are wrong with you': gender and the experience of multiple chronic conditions in later life. Ageing Soc 2013, 33(02):342-360. 
91. Taylor S, Greenhalgh T, Griffiths C, Pinnock H, Ribchester J, Sheikh A: A rapid synthesis of the evidence on interventions supporting self management for people with long-term conditions: report commissioned by the NIHR HTA Programme as project number 11/1014/04. NIHR HS \& DR. in press.

92. Bury M: Chronic illness as biographical disruption. Sociol Health IIIn 1982, 4(2):167-182.

93. Bury M: The sociology of chronic illness: a review of research and prospects. Sociol Health IIIn 1991, 13(4):451-468.

94. Farrimond $\mathrm{H}$ : Beyond the caveman: rethinking masculinity in relation to men's help-seeking. Health 2012, 16(2):208-225.

95. Galdas PM, Johnson JL, Percy ME, Ratner PA: Help seeking for cardiac symptoms: Beyond the masculine-feminine binary. Soc Sci Med 2010, 71(1):18-24.

96. Galdas PM: Men, Masculinity and Help-Seeking. In Men's Health: Body, Identity and Social Context. Edited by Broom A, Tovey P. London: John Wiley and Sons Inc; 2010.

97. Coulter A, Roberts S, Dixon A: Delivering Better Services for People with Long-Term Conditions: Building the House of Care. London: King's Fund; 2013.

98. Kidd LA: Consequences, control and appraisal: cues and barriers to engaging in self-management among people affected by colorectal cancer-a secondary analysis of qualitative data. Health Expect 2012, 17(4):565-578.

99. Pawson R, Greenhalgh T, Harvey G, Walshe K: Realist review-a new method of systematic review designed for complex policy interventions. J Health Serv Res Policy 2005, 10(suppl 1):21-34.

doi:10.1186/1471-2458-14-1230

Cite this article as: Galdas et al:: The accessibility and acceptability of self-management support interventions for men with long term conditions: a systematic review and meta-synthesis of qualitative studies. BMC Public Health 2014 14:1230.

\section{Submit your next manuscript to BioMed Central and take full advantage of:}

- Convenient online submission

- Thorough peer review

- No space constraints or color figure charges

- Immediate publication on acceptance

- Inclusion in PubMed, CAS, Scopus and Google Scholar

- Research which is freely available for redistribution 